\title{
D1 versus D2 dissection in gastric carcinoma: Evaluation of postoperative mortality and complications
}

\author{
Veli Vural, Barıș Saylam, Bülent Çomçalı, Arife Polat Düzgün, Mehmet Vasfi Özer, Faruk Coșkun
}

\section{ABSTRACT}

Clinic of $3^{\text {rd }}$ General Surgery Ankara Numune Training Hospital, Ankara, Turkey

This study was presented at the $17^{\text {th }}$ National Surgical Congress as a selected presentation, 26-29 May 2010, Ankara, Turkey

\section{Address for Correspondence Dr. Faruk Coşkun Clinic of 3rd General Surgery, Ankara Numune Training Hospital, Ankara, Turkey Phone.: +903125085241 e-mail: \\ farukcoskun@mynet.com}

Received: 03.12.2012

Accepted: 13.01.2013

(C) Copyright 2013 by Turkish Surgical Association

Available online at www.ulusalcerrahidergisi.org
Objective: Surgery is the only curative treatment for patients with gastric cancer. However, the extent of lymph node dissection is still debated. The aim of the study was to evaluate complications, postoperative length of hospital stay and postoperative mortality after D1 or D2 lymph node dissection for gastric cancer in a non-specialized hospital.

Material and Methods: All patients who underwent surgery for pathologically confirmed gastric cancer at our 3rd General Surgery Department, Ankara Numune Training Hospital between January 1999 and 2007 were retrospectively reviewed. A consecutive series of 71 gastric cancer patients was identified. D1 resection (level 1 lymphadenectomy) was compared with D2 resection (levels 1 and 2 lymphadenectomy).

Results: The D2 group had higher postoperative mortality ( $16 \%$ vs. $8 \%$; $p<0.005)$ and morbidity ( $54 \%$ vs. $34 \%$; $<<0.005)$, and their postoperative length of stay was longer. Splenectomy did not have an effect on postoperative morbidity and mortality in either the D1 or the D2 group.

Conclusion: The D2 procedure was associated with significantly higher postoperative mortality, morbidity, and postoperative length of hospital stay.

Key Words: Mortality, morbidity, gastric cancer, surgery

\section{INTRODUCTION}

Surgery has been adopted as the primary treatment for gastric cancer all over the world. The primary goal of surgical treatment is to provide cure. Curative treatment for gastric cancer is possible by diagnosis of the tumor at an early stage, applying the appropriate lymph node dissection, perioperative monitoring and providing an optimal level of treatment (1-4).

In this study, we aimed to evaluate the factors affecting morbidity and mortality in patients undergoing D1 and D2 lymph node dissection for gastric cancer by surgeons with low case volume in a general surgery unit that is not specialized in gastric surgery, and to review the literature.

\section{MATERIAL AND METHODS}

All patients who underwent surgery with a diagnosis of gastric cancer at the 3rd General Surgery Department, in Ankara Numune Training Hospital between January 1999 and 2007 were retrospectively reviewed, and 133 patients were identified. Of these patients, 26 patients with palliative procedures, 3 patients with a pathological diagnosis of neuroendocrine tumor or lymphoma and 33 patients with liver metastases were excluded from the study, leaving 71 patients in the study group. Their prospectively collected data were retrospectively evaluated.

Only patients who were operated with curative intent were included in the study. Their data regarding age, gender, co-morbidities, smoking, alcohol use, ASA score, albumin level, hemoglobin level, type of surgery and preoperative findings, additional procedures, postoperative early complications and mortality were evaluated.

Patients were classified according to age, as below or above 65 years. Co-morbid diseases such as diabetes, hypertension, chronic obstructive pulmonary disease and chronic liver disease were taken into account. Anesthesiologists determined the ASA score of our patients prior to operation. For comparative reasons patients with ASA score equal to or less than III were assessed in one group and those with ASA score of IV were accepted as another group.

The surgical intervention was recorded as two separate procedures, either total or subtotal gastrectomy, and the perioperative findings like tumor location, palpable lymph nodes and splenectomy were recorded in detail. 
D1 and D2 dissection was performed systematically as determined by the JRSSG (Japanese Research Society for the Study of Gastric Cancer) group (1). The perigastric lymph node stations that were located along the lesser curvature $\left(1,3\right.$, and $5^{\text {th }}$ stations) and the greater curvature $\left(2,4\right.$ and $6^{\text {th }}$ stations) were referred to as $\mathrm{N} 1$ group. The lymph nodes along the left gastric artery (no. 7), hepatic (no. 8), celiac (no. 9), and splenic arteries (no. 10,11) were named as N2 group.

D1 dissection was performed by including the small and greater omentum, with either a total or a subtotal resection of the stomach that contained lymph node stations 1-6. Spleen or pancreatic tail resections were included only in case of tumor invasion. D2 dissection was done by inclusion of the omental bursa, transverse mesocolon anterior leaf and complete excision of the gastric vascular pedicle contain 7-8-9 station lymph nodes. Spleen and/or pancreatic tail resection was applied in invasive tumors for complete clearance of stations 10 and 11 .

Early postoperative complications were defined as wound complications (seroma, hematoma, infection, evantration, evisceration, bleeding), anastomotic leak, pulmonary complications (pneumonia, pulmonary embolism, atelectasis, pleural effusion), cardiac complications (arrhythmias, DVT, myocardial infarction), renal complications (acute renal failure, urinary retention), pancreatitis, pancreatic fistula, intra-abdominal bleeding and intra-abdominal abscess formation within 30 days of surgery. Anastomotic leakage, pancreatic fistula, and intra-abdominal bleeding were accepted as major complications. D1 and D2 lymph node dissection groups were analyzed.

\section{Statistical Analysis}

Statistical Package for the Social Sciences (SPSS) 15.0 for Windows program was used for chi-square, analysis of variance (Mann-Whitney $U$ and Kruskal-Wallis) nonparametric tests in terms of statistical significance, with a $p$ value of $<0.05$ considered as statistically significant. When investigating the relationship between two numerical variables, Spearman's correlation coefficient was used.

\section{RESULTS}

Forty patients (56\%) were male and 31 (44\%) were female. Thirty-eight (54\%) patients were aged 65 years or younger, while $33(46 \%)$ were over 65 . The mean ages of female and male patients was 60 and 64, respectively.

The number of patients undergoing D1 lymph node dissection was $23(32 \%)$, while the number of patients who underwent D2 lymph node dissection was 48 (68\%). The mean age in D1 lymph node dissection group was 63 years, and the mean age of those who underwent D2 lymph node dissection was 61 years. D1 lymph node dissection group contained 11 female and 12 male patients, while the D2 lymph node dissection group consisted of 20 female and 28 male patients. There was no significant difference in terms of age or gender between D1 and D2 lymph node dissection groups ( $p>0.05$ ) (Table 1).

Anesthesiologists evaluated the general health status of our patients. Seventeen patients (73\%) were classified as ASA III or less and six patients (27\%) with ASA IV and above in the D1 lymph node dissection group, while the D2 lymph node dissection group included 38 patients (79\%) with ASA III or less and 10 patients $(21 \%)$ with ASA IV and above. There was no significant difference in terms of ASA scores between D1 and D2 lymph node dissection groups ( $p>0.05$ ).

After intraoperative assessment, 40 patients (56\%) underwent total gastrectomy, and 31 underwent (44\%) subtotal gastrectomy. In the total gastrectomy patients, $9(23 \%)$ received D1 lymph node dissection, and 31 (67\%) D2 lymph node dissection, while in the subtotal gastrectomy group $14(45 \%)$ had D1 lymph node dissection, and 17 (55\%) D2 lymph node dissection. D2 lymph node dissection rate in patients who underwent total gastrectomy, and D1 lymph node dissection rate in the subtotal gastrectomy group was significantly higher $(p<0.05)$ (Table 1).

Splenectomy was performed in eight of 23 patients (34\%) with D1 lymph node dissection, and in 25 of 48 patients (53\%) with D2 lymph node dissection. The splenectomy number in the D2 lymph node dissection group was significantly higher than the other group $(p<0.05)$ (Table 1). When analyzed according to stage, despite the majority of patients being at stage III, no difference was observed in stage distribution between the groups. The total number of lymph nodes and the number of metastatic lymph nodes removed was significantly higher in the D2 group (Table 1).

With regards to co-morbidities, 6 patients (26\%) had diabetes, 1 patient (4\%) had COPD and 8 patients (34\%) had hypertension in the D1 lymph node dissection group, and 6 patients (13\%) had diabetes, 2 patients (4\%) had COPD and 20 (42\%) had hypertension in the D2 lymph node dissection group (Table 2).

Seventeen patients had low albumin (24\%) values. It was found in 9 patients (39\%) in the D1 lymph node dissection group and in 8 patients (17\%) in the D2 lymph node dissection group (Table 2).

The number of patients with more than $10 \%$ weight loss in the last 6 months was 18 (78\%) in the D1 lymph node dissection group and 30 (62\%) in the D2 lymph node dissection group (Table 2). There was no significant correlation between D1 and D2 lymph node dissection groups and weight loss ( $p>0.05)$.

Early postoperative complications were identified in 34 patients (46\%) in both groups. The D1 lymph node dissection group had $8(34 \%)$, while the D2 lymph node dissection group had 26 (54\%) such patients. Comparing the sum of the major and minor complications, complications were significantly higher in the D2 lymph node dissection group $(\mathrm{p}<0.05)$ (Table 3 ).

Minor complications were identified in 6 patients (26\%) in the D1 lymph node dissection group and in 19 patients (39\%) in the D2 lymph node dissection group. However, major complications were seen in two patients (8\%) in the D1 lymph node dissection group and in 7 patients (15\%) in the D2 lymph node dissection group and this rate was significantly higher in the D2 lymph node dissection group $(p<0.05)$.

Within the D2 lymph node dissection group, 3 (6\%) patients developed pancreatic fistula, 2 (4\%), anastomotic leak, and 2 (4\%) abdominal bleeding was detected, whereas in the D1 lymph node dissection group one (4\%) pancreatic fistula and one (4\%) anastomotic leakage was detected as major compli- 
Table 1. Patient demographics, tumor properties and type of surgery according to dissection type

\begin{tabular}{|c|c|c|c|c|}
\hline D1 lyr & ph node dissection & D2 lymph node dissection & Total & $\mathrm{p}$ \\
\hline Age & $63 \pm 3.6$ & $61 \pm 2.8$ & $62 \pm 5.3$ & N.S. \\
\hline Gender (M/F) & $12 / 11$ & $28 / 20$ & 71 & N.S. \\
\hline \multicolumn{5}{|l|}{ ASA score } \\
\hline ASA III and below & 17 & 38 & 55 & \multirow[t]{2}{*}{ N.S. } \\
\hline ASA IV and above & 6 & 10 & 16 & \\
\hline \multicolumn{5}{|l|}{ Type of gastrectomy } \\
\hline Total & 9 & 31 & 40 & \multirow[b]{2}{*}{$\mathrm{p}<0.05$} \\
\hline Subtotal & 14 & 17 & 31 & \\
\hline Splenectomy & 8 & 25 & 33 & $\mathrm{p}<0.05$ \\
\hline \multicolumn{5}{|l|}{ Location } \\
\hline Antrum & 14 & 20 & 34 & \multirow{4}{*}{ N.S. } \\
\hline Corpus & 2 & 5 & 7 & \\
\hline Cardia & 6 & 14 & 20 & \\
\hline Linitis plastica & 1 & 1 & 2 & \\
\hline \multicolumn{5}{|l|}{ TNM Stage } \\
\hline I & 1 & 4 & 5 & \multirow{4}{*}{ N.S. } \\
\hline II & 7 & 9 & 16 & \\
\hline IIIA & 13 & 25 & 38 & \\
\hline IIIIB & 2 & 10 & 12 & \\
\hline Mean number of excised lymph nodes & $14.6 \pm 5.4$ & $31.8 \pm 16.1$ & $27.2 \pm 12.4$ & $\mathrm{p}<0.05$ \\
\hline Number of metastatic lymph nodes & $3.6 \pm 1.9$ & $11.1 \pm 6.1$ & $7.5 \pm 3.2$ & $\mathrm{p}<0.05$ \\
\hline
\end{tabular}

N.S.:Not Significant

Table 2. Co-morbidities and other factors

\begin{tabular}{|lccc|}
\hline & $\begin{array}{c}\text { Number of cases } \\
\text { in the D1 } \\
\text { lymph node } \\
\text { dissection group }\end{array}$ & $\begin{array}{c}\text { Number of cases } \\
\text { in the D2 } \\
\text { lymph node } \\
\text { dissection group }\end{array}$ & $\mathrm{p}$ \\
\hline DM & 6 & 6 & $\mathrm{p}<0.05$ \\
\hline COPD & 1 & 2 & N.S. \\
\hline HT & 8 & 20 & N.S. \\
\hline Smoking & 9 & 22 & N.S. \\
\hline Alcohol use & 2 & 5 & N.S. \\
\hline Low & 9 & 8 & p<0.05 \\
albumin level & 18 & 30 & N.S. \\
\hline Weight loss & 18 & \\
\hline N.S. Not Significant DM: Diabetes Mellitus, HT. Hypertension & \\
\hline
\end{tabular}

cations. Cardiopulmonary complications, as well as gastrointestinal complications such as pancreatic fistula, pancreatitis, and intra-abdominal bleeding were significantly higher in the D2 lymph node dissection group $(p<0.05)$ (Table 3 ).

Our mortality rate was $14 \%$ (10 patients). Two patients in the D1 lymph node dissection group (8\%) and 8 patients (16\%)
Table 3. Relation between dissection type and morbidity and mortality

Complications $\begin{gathered}\text { D1 lymph } \\ \text { D2 lymph } p\end{gathered}$

\begin{tabular}{|lccc|}
\hline Minor complications & 6 & 19 & $\mathrm{p}<0.05$ \\
\hline Respiratory & 2 & 3 & \\
\hline Cardiac & 0 & 3 & \\
\hline Renal & 1 & 4 & \\
\hline Wound infection & 3 & 11 & \\
\hline Pancreatitis & 0 & 2 & \\
\hline Major complications & 2 & 7 & $\mathrm{p}<0.05$ \\
\hline Anastomotic leak & 1 & 2 & \\
\hline Pancreatic fistula & 1 & 3 & \\
\hline Intraabdominal hemorrhage & 0 & 2 & \\
\hline Deep intraabdominal abscess & 1 & 6 & \\
\hline Duodenal stump leak & 0 & 1 & \\
\hline Total complication & $8^{*}$ & $27^{*}$ & $\mathrm{p}<0.05$ \\
\hline Mortality & 2 & 8 & $\mathrm{p}<0.05$ \\
\hline Length of hospital stay & $8.3 \pm 5.2$ & $11.3 \pm 8.7$ & $\mathrm{p}<0.05$ \\
\hline
\end{tabular}

*In some patients more than one complication was identified 
in the D2 lymph node dissection group were deceased. The mortality rate was significantly higher in the D2 lymph node dissection group as compared to D1 lymph node dissection $(p<0.05)$. Our main causes of mortality were as follows; one patient was lost due to pulmonary infection and one due to pancreatic fistula in the D1 lymph node dissection group. In only one of these patients diabetes, hypertension and chronic obstructive pulmonary disease was reported. In the D2 lymph node dissection patients 2 patients died due to pulmonary infection, 2 patients with myocardial infarction, 2 patients with pancreatic fistula, one patient with intra-abdominal abscess and one patient due to abdominal bleeding. Two of those patients had diabetes and hypertension, 2 had COPD and hypertension and in one had hypertension. Post-operative length of hospital stay was significantly high-

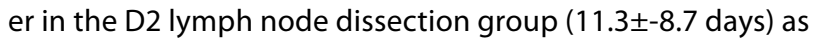
compared to those in the D1 lymph node dissection group (8.3+-5.2) (Table 3).

The complication and mortality rates in the D1 lymph node dissection and splenectomy group was $36 \%$ and $11 \%$, whereas these rates were $32 \%$ and $6 \%$ in the group with D1 lymph node dissection without splenectomy, respectively. The complication and mortality rates in the D2 lymph node dissection and splenectomy group was $56 \%$ and $15 \%$, and these rates were $52 \%$ and $13 \%$ in spleen protective D2 lymph node dissection patients, respectively. In D1 and D2 lymph node dissection, when groups with and without splenectomy were compared, there was no significant difference in terms of complications or mortality ( $p>0.05$ ) (Table 4).

\section{DISCUSSION}

It is certain that in developing countries such as our country, morbidity and mortality related to gastric surgery is affected by other factors with significant impact on surgical strategy. First, early detection and screening programs that evaluate patients with a high risk of gastric cancer is neither common nor effective in our country at the desired level, as they are in Japan and some European countries. In studies conducted in Europe and America, 30\% of patients have advanced gastric cancer, while this rate is around $21 \%$ in Japanese series $(2,3)$. In our series, advanced gastric cancer accounted for $58 \%$ of cases. The un-identification of high risk patients at an early stage by screening methods does not only increase the extent of surgical technique and lymph node dissection, but it also increases the effects of patient related factors such as late referral, advanced age, presence of serious underlying diseases, low levels of hemoglobin and protein levels, tumor localization and depth, decreasing the chance of curative surgery that has a direct effect on morbidity and mortality and in a way alters surgical strategy.

The most important point that makes early diagnosis vital for the treatment of gastric cancer is lymph node involvement. Studies have shown that even in early gastric cancer, lymph node involvement rate is between $5.7-13 \%$. The necessity and effectiveness of extended lymph node dissection is discussed, even in this group of patients. It is known that if the tumor is limited to the mucosa lymph node involvement risk is 3-5\%, if it is limited in the submucosa lymph node involvement rate is $11-25 \%$, the lymph node involvement rate is $50 \%$ in T2 tumors, and in $\mathrm{T} 3$ tumors the rate increases to $83 \%(4,5)$.
Another controversial point is the extent of the surgery. Japanese surgeons claims on longer overall survival and postoperative disease-free survival following perigastric, celiac, and splenic lymph node resection is doubted in the Western world, especially in America and studies on this issue are still in progress $(6,7)$. We also compared our gastric cancer patients, who underwent different approaches in terms of both gastric resection and lymph node dissection, for early postoperative morbidity and mortality. Nevertheless, when interpreting this comparison we have taken into account the facts that our patients were not detected by screening programs but consisted of patients with gastrointestinal complaints, that imaging methods applied for preoperative staging were not reported in light of standard expertise, that a significant portion of our patients was elderly, and with an advanced stage. We believe that, accepting surgical intervention or the extent of lymph node dissection as the only factors contributing to postoperative morbidity and mortality in our patient group would be incorrect.

During our review of the literature, we observed that Romania, a developing country as ours, showed in their 468 patients with gastric cancer that the patient's age, hemoglobin and protein levels and previous Billroth II operation had a significant effect on morbidity. Factors like gender, TNM stage, extent of surgical intervention, D1 or D2 lymph node dissection were not related to morbidity. Mortality was significantly higher in older age and male patients, and it was emphasized that low hemoglobin and protein levels, TNM stage determined by pathology, type of surgery and extent of lymph node dissection did not have an effect (8).

The mean age was 62 years in our series, 33 patients (46\%) were found to be older than and 38 patients (54\%) were younger than 65 years. Advanced age was not found to be a significant factor effecting morbidity and mortality in our series. Similarly, the male and female genders did not show a significant difference in terms of morbidity and mortality.

Another point of contention among Japanese and the Western world is the requirement of including organs such as the spleen and the pancreas in the surgical specimen. The principle defending that splenectomy should be included in the procedure is based on the opinion that effective dissection of lymph nodes around the splenic hilum and the splenic ar-

Table 4. Relation between splenectomy and complication and mortality

\begin{tabular}{|c|c|c|c|c|c|}
\hline & \multicolumn{2}{|c|}{ Complication } & \multicolumn{2}{|c|}{ Mortality } & \multirow[t]{2}{*}{ Total } \\
\hline & Yes & No & Yes & No & \\
\hline \multicolumn{6}{|c|}{ D1 lymph node dissection } \\
\hline $\begin{array}{l}\text { With } \\
\text { splenectomy }\end{array}$ & 3 & 5 & 1 & 7 & 8 \\
\hline $\begin{array}{l}\text { Without } \\
\text { splenectomy }\end{array}$ & 5 & 10 & 1 & 14 & 15 \\
\hline
\end{tabular}

D2 lymph node dissection

$\begin{array}{lccccc}\begin{array}{l}\text { With } \\ \text { splenectomy }\end{array} & 14 & 11 & 4 & 21 & 25 \\ \begin{array}{l}\text { Without } \\ \text { splenectomy }\end{array} & 12 & 11 & 2 & 21 & 23\end{array}$


tery can be achieved by this method. The possibility of splenic involvement in proximally located gastric cancer is approximately $10 \%$. Those opposing splenectomy base their theory on the facts that there is no significant prolongation in survival in those with splenectomy, besides a significant increase in the frequency of postoperative complications. Another hypothesis favoring this opinion is the belief that the spleen reduces the risk of early postoperative recurrence by suppressing tumor growth factor $(5,9)$.

In our study, out of the 25 patients with D2 lymph node dissection and splenectomy the complication rate was $56 \%$ with a mortality rate of $15 \%$, and out of the 23 patients with spleen protective D2 lymph node dissection $52 \%$ had complications with a mortality rate of $13 \%$. There was no significant difference in complication and mortality rates between the D2 lymph node dissection groups with or without splenectomy. Out of the 8 patients with D1 lymph node dissection and splenectomy the complication rate was $36 \%$ with a mortality rate of $11 \%$, and out of the 15 patients with spleen protective D1 lymph node dissection $32 \%$ had complications with a mortality rate of $6 \%$. There was no significant difference in complication and mortality rates between the D1 lymph node dissection groups with or without splenectomy.

Para-aortic lymph node metastases without peritoneal dissemination, adjacent organ invasion or distant metastasis was detected in $10 \%$ of cases by an extended lymph node dissection (10). Upgrading of the stage with detection of distant metastasis in a lymph node in distant location by extensive lymph node dissection is known as stage-shift or Will Rogers phenomenon. It is reported that in this way, a more accurate assessment of the stage and prognosis can be provided, but that survival will not be affected with extensive lymph node dissection, and morbidity and mortality will increase $(11,12)$. Removal of 26 or more lymph nodes is considered as radical lymph node dissection (13).

As radical gastrectomy and D2 lymph node dissection has become standard, oesophagojejunal anastomosis problems and deep venous thrombosis incidence have increased (14). In prospective randomized studies conducted in Europe, significant difference in survival was not found between D1- D2 and D1 -D3 resections $(15,16)$. In Chinese studies mortality and morbidity of D2 dissection was reported to be higher than D1 dissection, Finnish studies showed that D2 - 3 dissection had higher complication rates as compared to D1 dissection and in Europe D2 - 3 dissection is reported to carry an acceptable rate of mortality $(17,18)$. German series also reported that D3 dissection is not superior to D2 dissection and D3 dissection has disadvantages $(19,20)$. In our study, the greater omentum, D1 lymph node dissection, and 7, 8, 9 lymph nodes were removed as part of total gastrectomy. In some patients, 10 and 11 lymph nodes were also removed. D1 lymph nodes, and 7, 8,9 stations and the greater omentum was removed in distal subtotal gastrectomies. Para-aortic lymph node sampling was performed in 35 of 71 patients who were operated, and splenectomy was performed in 33. The type of lymph node dissection, especially D2 lymph node dissection compared to D1 lymph node dissection, was found to be a factor significantly increasing morbidity and mortality. On the other hand, extent of surgery, para-aortic lymph node sampling, and additional splenectomy did not have a significant effect on morbidity and mortality.

\section{CONCLUSION}

A retrospective review of 71 patients who underwent curative surgery in our clinics revealed significantly higher complications, mortality and length of hospital stay in the D2 lymph node dissection group as compared to D1 lymph node dissection group. As mentioned earlier, accepting the extent of lymph node dissection as the only reason for complications is inaccurate. Complication rates can vary even between different surgical groups within the same hospital (21). However, in a time where Western-based studies proving the positive impact of D2 lymph node dissection on disease-free survival are increasing, it would be wiser to propose increase in training of D2 lymph node dissection for gastric cancer, rather than advocating D1 lymph node dissection in low density, non-specialized clinics (22).

Peer-review: Externally peer-reviewed.

Author Contributions: Study concept and design - B.S., F.C., M.V.Ö.; Acquisition of data - V.V., B.Ç.; Analysis and interpretation of data - B.S., V. V., F. C.; Preparation of the manuscript - B.S., A.P.D., F.C.; Statistical analysis - V.V., B.S.

Conflict of Interest: No conflict of interest was declared by the authors.

Financial Disclosure: The authors declared that this study has received no financial support.

\section{REFERENCES}

1. Kajitani T. The general rules for gastric cancer study in surgery and pathology. Part I.Clinical classification. Jpn J Surg 1981; 11:127-39. [CrossRef]

2. Wanebo HJ, Kennedy BJ, Chmiel J, Steele G Jr, Winchester D, Osteen R. Cancer of stomach. A patient care study by the American College of Surgeon. Ann Surg 1993; 218: 583-92. [CrossRef]

3. Kodera Y, Yamamura Y, Torii A, Uesaka K, Hirai T, Yasui K, et al. Postoperative staging of gastric carcinoma. A comparison between the UICC Stage Classification and the 12.edition of the Japanese General Rules for Gastric Cancer Study. Scand J Gastroenterol 1996; 31: 476-80. [CrossRef]

4. Maruyama K, Gunven P, Okabayashi K, Sasako M, Kinoshita T. Lymph node metastases of gastric cancer general patern in 1931 patients. Ann Surg 1999; 210: 596-602. [CrossRef]

5. Sano T, Yamamoto S, Sasako M. Randomızed controlled trial to evaluate splenectomy in total gastrectomy for proximal gastric carcinoma: Japan Clinical Oncology Group Study JCOG 0110-MF. Japanese J Clin Oncol 2002; 32: 363-4. [CrossRef]

6. Candela G, Sergio V, Di Libero L, Manetta F, Giordano M, Scetta G, et al. Prognostic and therapautic value of $D 2$ lynphadenectomy in the treatment of gastric cancer:experince of an Italian team. Chir Ital 2008; 60: 675-84.

7. Roviello F, Marrelli D, Morgagni P, de Manzoni G, Di Leo A, Vindigni $C$, et al. Survival Benefit of Extended D2 Lymphadenectomy in Gastric Cancer With Involvement of Second Level Lynph Nodes: A Longitudinal Multicenter Study 2002; 9: 894-900.

8. Necula A, Vlad L, lancu C, Munteanu D, Puia C, Bălă O, et al. Morbidity and mortality in gastric cancer surgery-analysis of 468 cases with gastric adenocarcinoma. Chirurgia (Bucur) 2008; 103: 529-37.

9. Lee KY, Noh SH, Hyung WJ, Lee JH, Lah KH, Choi SH, et al. Impact of splenectomy for lymph node dissection on long-term surgical outcome in gastric cancer. Ann Surg Oncol 2001; 8: 402-6. [CrossRef]

10. Kodera $Y$, Yamamura $Y$, Shimizu Y, Torii A, Hirai T, Yasui $K$, et al. Metastatic gastric Imph node rate is a significant prognostic fac- 
Vural et al.

D1 versus D2 dissection in stomach carcinoma

tor for resectable stage IV stomach cancer. J Am Coll Surg 1997; 185: 65-9. [CrossRef]

11. Sah BK, Zhu ZG, Chen MM, Yan M, Yin HR, Zhen LY. Gastric cancer surgery and its hazards: postoperative infections is the most important complication. Hepatogastroenterology 2008; 55: 259-63.

12. Bunt AM, Hermans J, Smit VT, van de Velde CJ, Fleuren GJ, Bruijn $J A$. Surgical/pathologic-stage migration confounds comparisons of gastric cancer survival rates between Japan and Western countries. J Clin Oncol 1995; 13: 19-25.

13. Siewert JR, Bottcher K, Roder JD, Busch R, Hermanek P, Meyer HJ. Prognostic relevance of systemic lymph node dissection in gastric carcinoma. German Gastric Carcinoma Study Group. Br J Surg 1993, 80: 1015-8. [CrossRef]

14. Rifatbegovic Z, Mesic D. Total gastrectomy and systematic lymphadenectomy complications. Med Arh 2006; 60: 29-33.

15. Dent DM, Madden MV, Price SK. Randomized comparison of R 1 and R 2 gastrectomy for gastric carcinoma. Br J Surg 1988; 75: 110-2. [CrossRef]

16. Robertson CS, Chung SC, Woods SD, Griffin SM, Raimes SA, Lau $\mathrm{JT}$, et al. A prospective randomized trial comparing $\mathrm{R} 1$ subtotal gastrectomy with $\mathrm{R} 3$ total gastrectomy for antral cancer. Ann Surg 1994; 220: 176-82. [CrossRef]
17. Wang XF, Sun YH, Liang DJ, Wang C, Fang Y, Liu TS, et al. Clinical values of extended lymph node dissection for gastric cancer: a metaanalysis for D1 versus D2 gastrectomy. Zhonghua Wei Chang Wai Ke Za Zhi 2007; 10: 425-30.

18. Danielson H, Kokkola A, Kiviluoto T, Siren J, Louhimo J, Kivilaakso E, et al. Clinical outcome after D1 vs D2-3 gastrectomy for treatment of gastric cancer. Scand J Surg 2007; 96: 35-40.

19. Bittorf BR, Günther F, Merkel S, Horbach T, Hohenberger W, Günther K. D3 versus D2 dissection in stomach carcinoma. A case-control study of postoperative morbidity, survival and early oncologic outcome. Chirurg 2002; 73: 336-47. [CrossRef]

20. Günther K, Horbach T, Merkel S, Meyer M, Schnell U, Klein P, et al. D3 lymph node dissection in gastric cancer: evaluation of postoperative mortalıty and complications. Surg Today 2000; 30: 700-5. [CrossRef]

21. Yüksel BC, Uçar NS, Yıldız Y, Berkem H, Özel H, Hengirmen S. Morbidity and mortality of Standard D1 versus D2 dissection in gastric cancer. Ulusal Cerrahi Dergisi 2009; 25: 87-91.

22. Songun I, Putter $H$, Kranenbarg EM, Sasako M, van de Velde CJ. Surgical treatment of gastric cancer: 15-year follow-up results of the randomised nationwide Dutch D1D2 trial. Lancet Oncol 2010; 11: 439-49. [CrossRef] 